
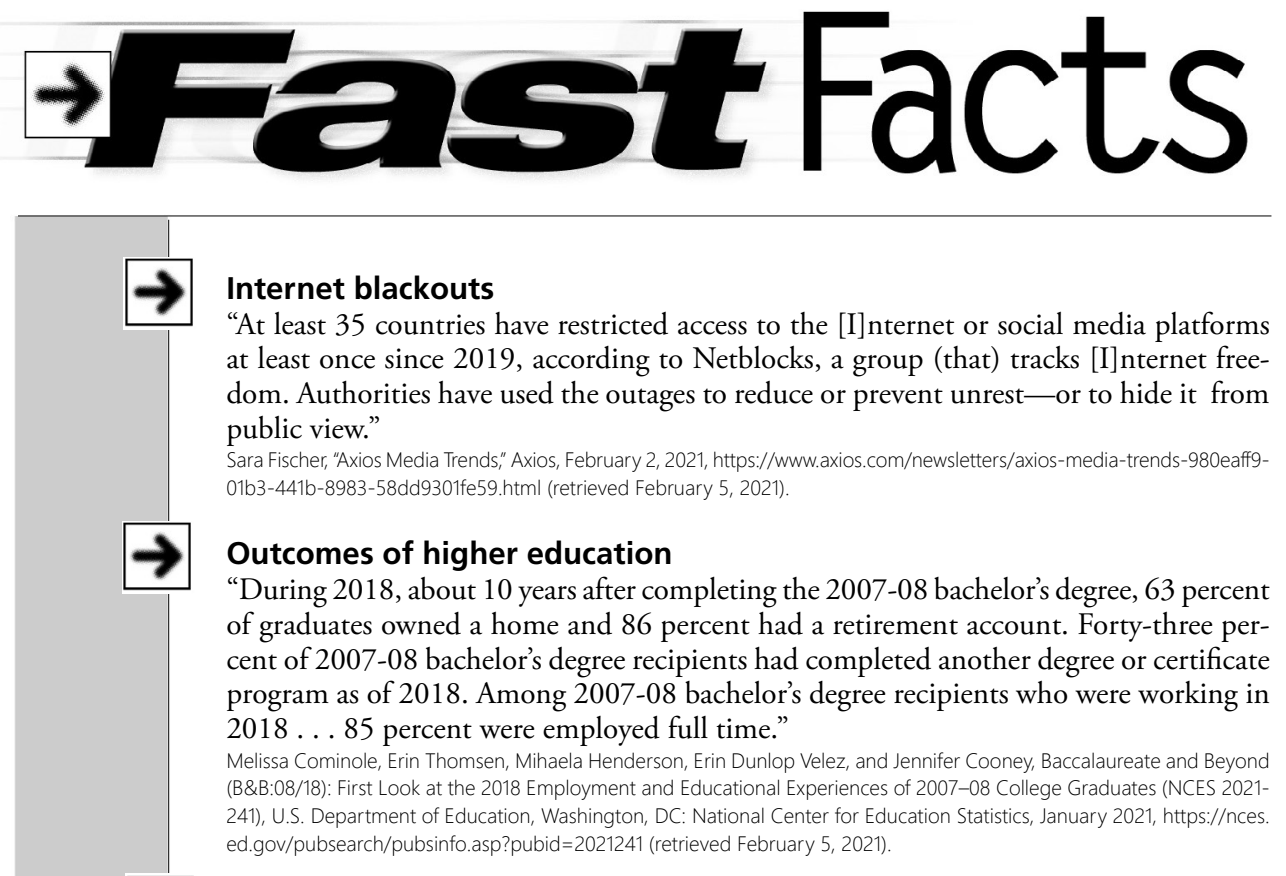

\title{
Freedom of Information Act requests
}

"More Freedom of Information Act (FOIA) requests were filed during the past four years than at any time in American history, per the FOIA Project, a non-profit project that gathers comprehensive information on federal FOIA decisions. During the Trump administration, the media filed a total of 386 FOIA cases. That's more than all of the FOIA cases filed by the media during the 16 years of the Bush and Obama administrations combined."

Sarah Fischer, "Axios Media Trends," January 19, 2021, https://www.axios.com/newsletters/axios-media-trends-13b9540aea69-4942-95cc-3c80d6682783.html (retrieved January 19, 2021).

\section{Digitized presidential collections}

"The Library of Congress has completed a more than two decade-long initiative to digitize the papers of nearly two dozen early presidents. The Library holds the papers of 23 presidents from George Washington to Calvin Coolidge, all of which have been digitized and are now available online."

"Library of Congress Completes Digitization of 23 Early Presidential Collections," BCTV, December 23, 2020, https://www.bctv org/2020/12/23/library-of-congress-completes-digitization-of-23-early-presidential-collections (retrieved February 5, 2021).

\section{College students amid COVID-19}

"A third of all currently enrolled students pursuing their bachelor's degree in the fall of 2020 [reported] they [had] considered stopping their coursework in the [previous] six months. Among these students, 15 percent say they considered stopping because the education they were receiving was low quality. However, quality is not a top concern; COVID-19 (51 percent), emotional stress ( 42 percent) and cost of attendance ( 33 percent) are the most frequently cited reasons."

Stephanie Marken, "College Students Report Quality Experience Amid COVID-19," Gallup.com, December 15, 2020, https://news.gallup.com/opinion/gallup/327713/college-students-report-quality-experience-amid-covid.aspx (retrieved February 5, 2021).

Gary Pattillo is reference librarian at the University of North Carolina-Chapel Hill, e-mail: pattillo@email.unc.edu 